\title{
Front Matter: Volume 9847
}

, "Front Matter: Volume 9847," Proc. SPIE 9847, Anomaly Detection and Imaging with X-Rays (ADIX), 984701 (10 June 2016); doi:

$10.1117 / 12.2244794$

SPIE. Event: SPIE Defense + Security, 2016, Baltimore, MD, United States 


\title{
PROCEEDINGS OF SPIE
}

\section{Anomaly Detection and Imaging with X-Rays (ADIX)}

\author{
Amit Ashok \\ Mark A. Neifeld \\ Michael E. Gehm \\ Editors
}

19-20 April 2016

Baltimore, Maryland, United States

Sponsored and Published by

SPIE 
The papers in this volume were part of the technical conference cited on the cover and title page. Papers were selected and subject to review by the editors and conference program committee. Some conference presentations may not be available for publication. Additional papers and presentation recordings may be available online in the SPIE Digital Library at SPIEDigitallibrary.org.

The papers reflect the work and thoughts of the authors and are published herein as submitted. The publisher is not responsible for the validity of the information or for any outcomes resulting from reliance thereon.

Please use the following format to cite material from these proceedings:

Author(s), "Title of Paper," in Anomaly Detection and Imaging with X-Rays (ADIX), edited by Amit Ashok, Mark A. Neifeld, Michael E. Gehm, Proceedings of SPIE Vol. 9847 (SPIE, Bellingham, WA, 2016) Six-digit Article CID Number.

ISSN: 0277-786X

ISSN: 1996-756X (electronic)

ISBN: 9781510600881

Published by

SPIE

P.O. Box 10, Bellingham, Washington 98227-0010 USA

Telephone +1 3606763290 (Pacific Time) · Fax +1 3606471445

SPIE.org

Copyright (C) 2016, Society of Photo-Optical Instrumentation Engineers.

Copying of material in this book for internal or personal use, or for the internal or personal use of specific clients, beyond the fair use provisions granted by the U.S. Copyright Law is authorized by SPIE subject to payment of copying fees. The Transactional Reporting Service base fee for this volume is $\$ 18.00$ per article (or portion thereof), which should be paid directly to the Copyright Clearance Center (CCC), 222 Rosewood Drive, Danvers, MA 01923. Payment may also be made electronically through CCC Online at copyright.com. Other copying for republication, resale, advertising or promotion, or any form of systematic or multiple reproduction of any material in this book is prohibited except with permission in writing from the publisher. The CCC fee code is 0277-786X/16/\$18.00.

Printed in the United States of America.

Publication of record for individual papers is online in the SPIE Digital Library.

\section{SPIE. DIGITAL}

Paper Numbering: Proceedings of SPIE follow an e-First publication model. A unique citation identifier (CID) number is assigned to each article at the time of publication. Utilization of CIDs allows articles to be fully citable as soon as they are published online, and connects the same identifier to all online and print versions of the publication. SPIE uses a six-digit CID article numbering system structured as follows:

- The first four digits correspond to the SPIE volume number.

- The last two digits indicate publication order within the volume using a Base 36 numbering system employing both numerals and letters. These two-number sets start with 00, 01, 02, 03, 04, $05,06,07,08,09,0 A, 0 B \ldots$ OZ, followed by 10-1Z, 20-2Z, etc. The CID Number appears on each page of the manuscript. 


\title{
Contents
}

\author{
vii Authors \\ ix Conference Committee \\ xi Introduction
}

\section{SESSION 1 KEYNOTE AND INAUGURAL SESSION}

984702 Aviation security x-ray detection challenges (Invited Paper) [9847-2]

\section{SESSION $2 \quad$ X-RAY SCATTER AND PHASE ANOMALY IMAGING AND DETECTION I}

984704 Detecting liquid threats with $\mathrm{x}$-ray diffraction imaging (XDi) using a hybrid approach to navigate trade-offs between photon count statistics and spatial resolution (Invited Paper) [9847-3]

984706 Snapshot full-volume coded aperture x-ray diffraction tomography (Invited Paper) [9847-5]

\section{SESSION $3 \quad$ X-RAY SCATTER AND PHASE ANOMALY IMAGING AND DETECTION II}

984709 Absorption-phase duality in structured illumination transport of intensity (TIE) phase imaging [9847-8]

9847 OA Multi-view coded aperture coherent scatter tomography [9847-9]

$9847 \mathrm{OB}$ Information-theoretic analysis of $\mathbf{x}$-ray scatter and phase architectures for anomaly detection [9847-10]

9847 OC Phase and coherent scatter imaging for improved discrimination of low-density materials [9847-11]

\section{SESSION $4 \quad$ X-RAY PHOTOABSORPTION ANOMALY IMAGING AND DETECTION}

9847 OD CT dual-energy decomposition into x-ray signatures pe and Ze (Invited Paper) [9847-12]

9847 OE High precision, medium flux rate CZT spectroscopy for coherent scatter imaging (Invited Paper) [9847-13]

9847 OF Information-theoretic analysis of $\mathbf{x}$-ray photoabsorption based threat detection system for check-point [9847-14]

9847 OG High frame-rate real-time x-ray imaging of in situ high-velocity rifle bullets [9847-15] 
$9847 \mathrm{OH} \quad$ Shape threat detection via adaptive computed tomography [9847-16]

\section{SESSION $5 \quad X$-RAY CT RECONSTRUCTION AND EXPLOITATION ALGORITHMS I}

9847 0J Performance analysis of model based iterative reconstruction with dictionary learning in transportation security CT [9847-18]

9847 OK Model-based reconstruction for x-ray diffraction imaging [9847-19]

$9847 \mathrm{OL} \quad$ 2.5D dictionary learning based computed tomography reconstruction [9847-20]

SESSION $6 \quad X$ X-RAY CT RECONSTRUCTION AND EXPLOITATION ALGORITHMS II

9847 OM Extraction and classification of 3D objects from volumetric CT data (Invited Paper) [9847-21]

9847 ON Tackling the $x$-ray cargo inspection challenge using machine learning [9847-22]

$984700 \quad$ CT reconstruction via denoising approximate message passing [9847-23]

9847 OP Optimizing convergence rates of alternating minimization reconstruction algorithms for real-time explosive detection applications [9847-24]

9847 OQ Rapid GPU-based simulation of x-ray transmission, scatter, and phase measurements for threat detection systems [9847-25]

9847 OR Domain and range decomposition methods for coded aperture x-ray coherent scatter imaging [9847-26]

\section{SESSION $7 \quad$ X-RAY SYSTEM DESIGN/ANALYSIS AND FORWARD-MODEL}

9847 OS Figures of merit for optimizing imaging systems on joint estimation/detection tasks (Invited Paper) [9847-27]

9847 OT Information optimal compressive x-ray threat detection [9847-28]

9847 OU Estimation and detection information trade-off for $x$-ray system optimization [9847-29]

9847 OV Robust x-ray based material identification using multi-energy sinogram decomposition [9847-30]

9847 OW Spectral feature variations in x-ray diffraction imaging systems [9847-31]

9847 0X Impact of detector geometry for compressive fan beam snapshot coherent scatter imaging [9847-32] 
9847 OY Partially observable Markov decision processes for risk-based screening [9847-35]

INTERACTIVE POSTER SESSION

$98470 Z$ Data sinogram sparse reconstruction based on steering kernel regression and filtering strategies [9847-33] 
Proc. of SPIE Vol. $9847984701-6$

Downloaded From: https://www.spiedigitallibrary.org/conference-proceedings-of-spie on 26 Apr 2023 Terms of Use: https://www.spiedigitallibrary.org/terms-of-use 


\section{Authors}

Numbers in the index correspond to the last two digits of the six-digit citation identifier (CID) article numbering system used in Proceedings of SPIE. The first four digits reflect the volume number. Base 36 numbering is employed for the last two digits and indicates the order of articles within the volume. Numbers start with 00, 01, 02, 03, 04, 05, 06, 07, 08, 09, OA, OB...0Z, followed by 10-12, 20-2Z, etc.

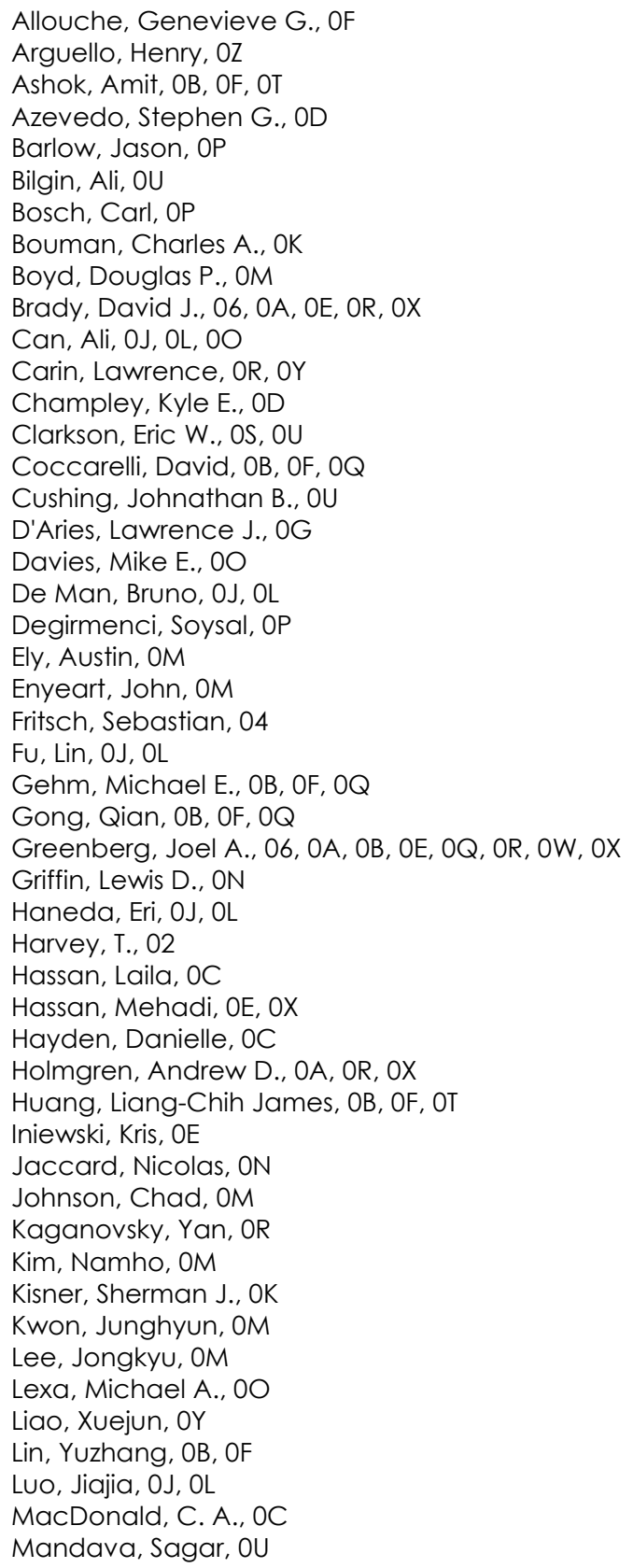


Proc. of SPIE Vol. $9847984701-8$

Downloaded From: https://www.spiedigitallibrary.org/conference-proceedings-of-spie on 26 Apr 2023 Terms of Use: https://www.spiedigitallibrary.org/terms-of-use 


\section{Conference Committee}

Symposium Chair

David Logan, BAE Systems (United States)

Symposium Co-chair

Donald A. Reago Jr., U.S. Army Night Vision \& Electronic Sensors

Directorate (United States)

\section{Conference Chairs}

Amit Ashok, College of Optical Sciences, The University of Arizona (United States)

Mark A. Neifeld, The University of Arizona (United States)

Michael E. Gehm, Duke University (United States)

\section{Conference Program Committee}

Mark A. Anastasio, Washington University in St. Lovis (United States)

George Barbastathis, Massachusetts Institute of Technology (United States)

Ali Bilgin, The University of Arizona (United States)

Eric W. Clarkson, The University of Arizona (United States)

Edward D. Franco, Rapiscan Systems Laboratories (United States)

Joel A. Greenberg, Duke University (United States)

Tim E. Harvey, EMF Corporation (United States)

Kris Iniewski, Redlen Technologies (Canada)

Eric A. Johnson, SureScan Corporation (United States)

Robert R. Muise, Lockheed Martin Missiles and Fire Control

(United States)

Joseph A. O'Sullivan, Washington University in St. Louis (United States)

Lei Tian, University of California, Berkeley (United States)

Session Chairs

Opening Remarks and Conference Inauguration

Mark A. Neifeld, The University of Arizona (United States)

Amit Ashok, College of Optical Sciences, The University of Arizona (United States)

Michael E. Gehm, Duke University (United States)

Sharene Young, U.S. Dept. of Homeland Security (United States) 
1 Keynote and Inaugural Session

Sharene Young, U.S. Dept. of Homeland Security (United States)

2 X-ray Scatter and Phase Anomaly Imaging and Detection I

Lei Tian, University of California, Berkeley (United States)

3 X-ray Scatter and Phase Anomaly Imaging and Detection II

Kris Iniewski, Redlen Technologies (Canada)

4 X-ray Photoabsorption Anomaly Imaging and Detection

Michael E. Gehm, Duke University (United States)

5 X-ray CT Reconstruction and Exploitation Algorithms I

Mark A. Neifeld, The University of Arizona (United States)

6 X-ray CT Reconstruction and Exploitation Algorithms II

Amit Ashok, College of Optical Sciences, The University of Arizona (United States)

7 X-ray System Design/Analysis and Forward-model

Joseph A. O'Sullivan, Washington University in St. Lovis (United States) 


\section{Introduction}

We would like to begin by thanking everyone who participated in the inaugural SPIE Anomaly Detection and Imaging with X-Rays (ADIX) conference. It is our hope that this will be the first of many such meetings that can bring together the broad range of expertise/interest characterizing this important discipline. Indeed, this first meeting involved participation by all segments of the community, government, industry, and academia, resulting in a vibrant and intellectually rewarding forum for exchange of ideas.

Although x-ray imaging has its roots in medical imaging, advances in x-ray component technology coupled with the exponential growth in computational capability has fueled the expansion of $x$-ray imaging to numerous defense and security applications. For example, $x$-ray based imaging systems are now widely deployed at security checkpoints for explosive and contraband detection at airports, seaports, commercial and military building and installations. Another modern application of $x$-ray imaging is non-destructive part inspection for industrial and aviation safety. While the application base for $\mathrm{X}$-ray based anomaly detection and imaging continues to grow, the $x$-ray imaging system architecture (inspired by medical CT) has remained largely unchanged. However, recently non-traditional $x$-ray imaging architectures and sophisticated post-processing algorithms have begun to emerge which leverage advances in mathematical theory of sampling (e.g. compressive sensing) together with increased exploitation of available signal and task prior information.

Reviewing the collection of excellent talks that were presented at the meeting, it was clear that the conference provided a much needed venue for researchers to address current and future challenges through advances in all aspects of x-ray based anomaly detection and imaging: ranging from component technology, reconstruction and data exploitation algorithms, imaging/sensing system architectures to system performance metrics and novel defense and security applications.

The conference began with a very engaging keynote address [9847-2] by Dr. Eric Houser from the United States Transportation Security Administration (TSA) who described not only the substantial technical challenges associated with explosive threat detection in airports, but also the regulatory, administrative; and 'ecosystem' challenges that arise from the combination of government, industry, and academic participants in this important enterprise.

Following the keynote address, the ADIX conference was organized into four Session Topic Areas (STAs), the first of which was X-Ray Scatter and Phase Anomaly Imaging and Detection. A plurality of papers in this STA describe research projects 
related to novel measurement architectures and reconstruction methods for exploiting Raleigh scattering for materials identification and liquid/low-density threat detection. Taken together these papers illuminate some of the tradeoffs associated with scatter-based x-ray measurements in both the scanning and snapshot modalities. Also in this STA we find several excellent papers on the topic of $x$-ray phase measurement presenting new ideas about sources, detectors, and phase retrieval algorithms and the information theoretic limits of this novel modality.

The next STA on day one was X-ray Photoabsorption Anomaly Imaging and Detection and these papers described various refinements for improving the performance of dual-energy, multi-energy, multi-angle, and/or adaptive measurements in the photo-absorption modality.

On day two of ADIX we began with the STA X-ray CT Reconstruction and Exploitation Algorithms. The ten papers in this STA described how the latest advances in nonlinear optimization, machine learning, and graphical inference can be applied to all of the modalities discussed during day one. As a testament to the importance of these advanced algorithms, many of these papers describe numerical acceleration to enable real-time operation.

Our last STA was X-ray System Design/Analysis and Forward-model and the six paper in this STA addressed a multitude of important topics related to the rapid simulation of $x$-ray/matter interaction physics, development and application of system design and decision metrics.

From this brief overview of the papers presented at the inaugural ADIX conference, it was clear that the field of Anomaly Detection and Imaging with X-Rays is currently experiencing significant innovation. The papers included in this volume describe important advances on many of the topics described in our original call for papers such as coded-apertures designs, non-traditional system architectures, coherent and incoherent scatter, phase-contrast based x-ray imaging/sensing systems, adaptive measurement, task-specific system design, and compressive scan geometries for direct and reconstruction-based anomaly detection/estimation.

\section{Amit Ashok Mark A. Neifeld Michael E. Gehm}

